\title{
NLRPs, the subcortical maternal complex and genomic imprinting
}

\author{
David Monk ${ }^{1}$, Marta Sanchez-Delgado ${ }^{1}$ and Rosemary Fisher ${ }^{2,3}$ \\ ${ }^{1}$ Imprinting and Cancer Group, Cancer Epigenetic and Biology Program, Institut d'Investigació Biomedica de \\ Bellvitge, Hospital Duran i Reynals, Barcelona, Spain, ${ }^{2}$ Imperial Centre for Translational and Experimental Medicine, \\ Imperial College London, London, UK and ${ }^{3}$ Trophoblastic Tumour Screening and Treatment Centre, Department of \\ Oncology, Imperial College London, London, UK
}

Correspondence should be addressed to D Monk; Email: dmonk@idibell.cat

\begin{abstract}
Before activation of the embryonic genome, the oocyte provides many of the RNAs and proteins required for the epigenetic reprogramming and the transition to a totipotent state. Targeted disruption of a subset of oocyte-derived transcripts in mice results in early embryonic lethality and cleavage-stage embryonic arrest as highlighted by the members of the subcortical maternal complex (SCMC). Maternal-effect recessive mutations of NLRP7, KHDC3L and NLRP5 in humans are associated with variable reproductive outcomes, biparental hydatidiform moles (BiHM) and widespread multi-locus imprinting disturbances. The precise mechanism of action of these genes is unknown, but the maternal-effect phenomenon suggests a function during early pre-implantation development, while biochemical and genetic studies implement them as SCMC members or interacting partners. In this review article, we discuss the role of the NLRP family members and the SCMC proteins in the establishment of genomic imprints and post-zygotic methylation maintenance, the recent advances made in the understanding of the biology involved in BiHM formation and the wider roles of the SCMC in mammalian reproduction.

Reproduction (2017) 154 R161-R170
\end{abstract}

\section{Oocyte development}

During folliculogenesis, the growth of the oocytes is linked to the proliferation and differentiation of the surrounding granulosa cells (Fig. 1). Follicle development is a prolonged and complex process during which time female primordial germ cells enter meiosis and arrest at the diplotene stage of meiotic prophase I. These primary oocytes, contained within the primordial follicle, then periodically enter the growth phase in response to the luteinizing hormone surge, which culminates in meiotic maturation, expulsion of the first polar body and ovulation. Meiosis is then resumed and finally completed when a sperm penetrates the oocyte at fertilization, which triggers $\mathrm{Ca}^{2+}$-induced cyclin degradation allowing for the completion of meiosis II and the exclusion of the second polar body (Amleh \& Dean 2002). During the process of oogenesis, there is continual cross-talk between the nucleus and cytoplasm, which is essential for oocyte maturation, epigenetic patterning and the developmental potential of pre-implantation embryo. In addition, there is the accumulation of maternal proteins that are of importance not only for the oocyte, but also for the cellular processes that occur before embryonic genome activation (EGA) (Table 1 for full list of abbreviations) during the cleavage stages of pre-implantation development (Clift \& Schuh 2013).

\section{Methylation acquisition in the oocyte}

The correct establishment of DNA methylation is essential for the successful development of the embryo following fertilization, primarily due to the necessity for epigenetic marking of genomic imprints (Monk 2015). Following the widespread epigenetic erasure that occurs in the primordial germ cells, oocytes acquire a unique methylation landscape compared to somatic cells (Smallwood et al. 2011, Kobayashi et al. 2012, SanchezDelgado et al. 2016). Since many methylated domains are located in genes expressed in the oocyte, many of which are solely observed in the developing oocyte, the process of transcription is thought to be a prerequisite for methylation establishment (Chotalia et al. 2009, Veselovsha et al. 2015). Data from mice have shown that DNA methylation is fully established in the germinal vesicle stage-ovulated metaphase ll oocytes, but that there is a degree of asynchrony at earlier stages (Gahurova et al. 2017). Such asynchrony may reflect the requirement for specific factors in addition to the core de novo complex comprising DNA methyltransferase 3A (DNMT3A) and its obligated partner DNMT3-like (DNMT3L) (Bourc'his et al. 2001, Kaneda et al. 2004). The acquisition of de novo methylation in the female germline depends upon the absence of H3K4 methylation (Ooi et al. 2007), as 


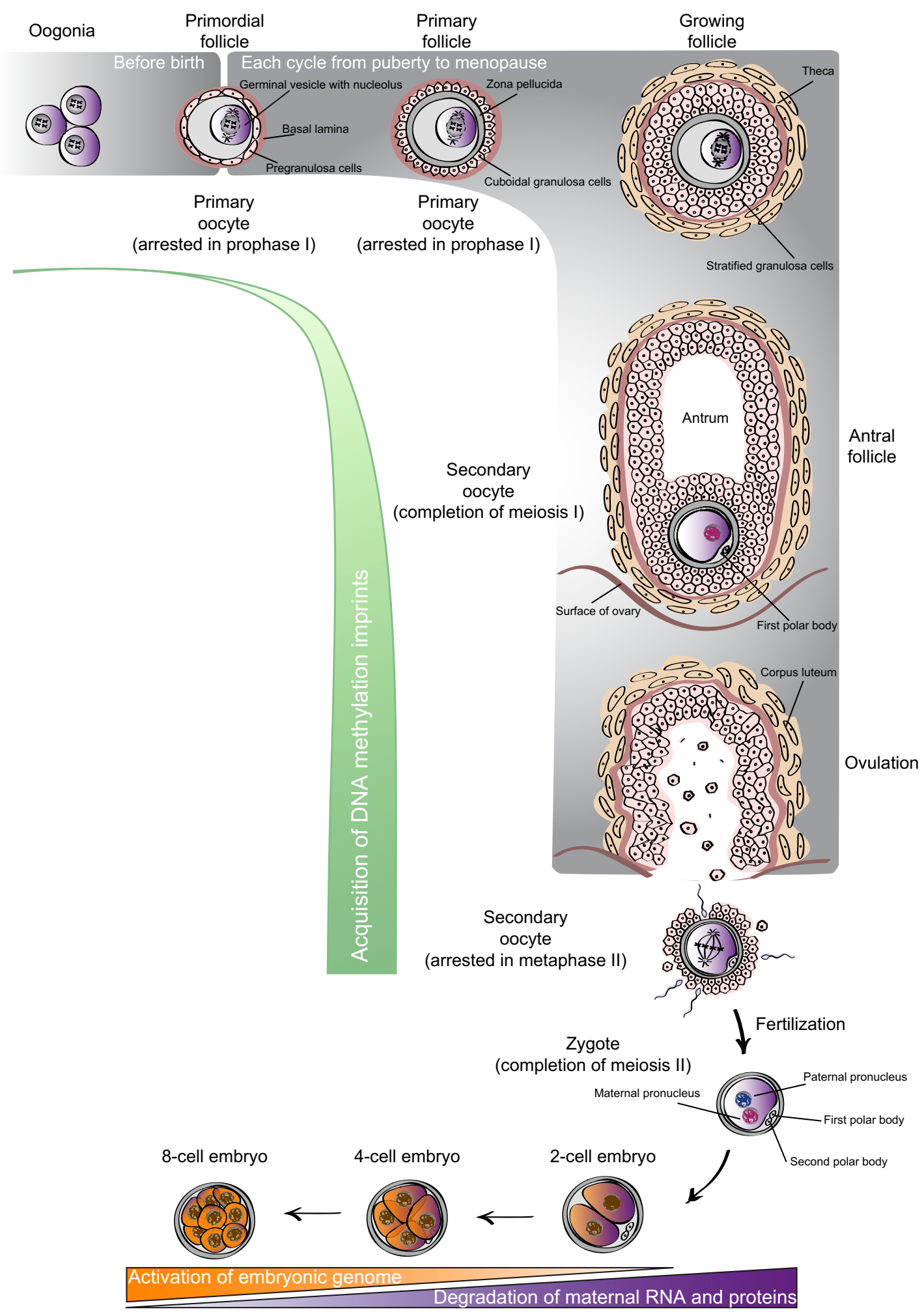

Figure 1 Overview of oocyte maturation and early embryo development in humans. From birth the ovaries contain a decreasing number of immature primordial follicles that each contain an immature primary oocyte. These oocytes have undergone meiotic DNA replication, are arrested in meiotic prophase and are surrounded by somatic cells. Sporadically, some of these primordial follicles initiate a prolonged growth phase in which the supporting cells proliferate and oocytes increase in size, accumulating the maternal factors necessary to support the early embryo. From this time onwards, DNA methylation imprints are progressively established. Every menstrual cycle, in response to the gonadotropin surge, meiosis resumes to metaphase II resulting in a mature oocyte. Meiosis is only completed on fertilization, which initiates a cascade of events in the early embryo that includes mitotic cleavage division and embryonic genome activation. 
Table 1 A list of abbreviations used in this review.

\begin{tabular}{ll}
\hline Abbreviation & Description \\
\hline $5 \mathrm{mC}$ & 5-Methylcytosine \\
$5 \mathrm{hmC}$ & 5-Hydromethylcytosine \\
BiHM & Biparental hydatidiform moles \\
CHM & Complete hydatidiform moles \\
EGA & Embryonic genome activation \\
FRHM & Familial recurrent hydatidiform moles \\
H3K & Histone 3 lysine \\
IVF & In vitro fertilization \\
ICSI & Intracytoplasmic sperm injection \\
MLID & Multi-locus imprinting disturbance \\
SCMC & Subcortical maternal complex \\
Gene abbreviation & Gene name \\
CDKN1C & Cyclin-dependent kinase inhibitor 1C \\
DNMTS & DNA methyltransferases \\
DPPA3 & Developmental pluripoyency associated 3 \\
GNAS & Guanine nucleotide binding protein \\
IGF1R & Insulin-like growth factor 1 receptor \\
KCNQ1OT1 & KCNQ1 Opposite Strand/Antisense Transcript 1 \\
KDM1B & Lysine-specific histone demethylase 1B \\
KHDC3L & KH Domain-Containing 3-Like \\
MEST & Mesoderm-Specific Transcript \\
NAP1L5 & Nucleosome Assembly Protein 1 Like 5 \\
NLRP family & NLR family, Pyrin domain containing \\
OOEP & Oocyte Expressed Protein \\
PEG3 & Paternally expressed gene 3 \\
PEG10 & Paternally expressed gene 10 \\
RB1 & Retinoblastoma 1 \\
SNRPN & Small Nuclear Ribonucleoprotein Polypeptide N \\
TETS & 10-11 translocation proteins \\
TLE6 & Transducin-Like Enhancer of Split 6 \\
TRIM28 & Trin Yantite motif containing 28 \\
YY1 & Zinc finger and BTB domain containing 16 \\
ZBTB16 & Zinc finger protein 57 \\
ZFP57 & \\
\hline &
\end{tabular}

revealed by the essential role of lysine-specific histone demethylase 1B (KDM1B) (Ciccone et al. 2009), and probably the deposition of H3K36me3 (Baubec et al. 2015), a histone modification associated with the elongating Polll complex. It is currently unknown if the mechanism of methylation establishment is the same in humans as several differences have been observed. For example, despite DNMT3L having no catalytic activity, this co-factor is essential for the establishment of all germline-derived maternally methylated imprinted regions in mice, but DNMT3L is not expressed in human oocytes (Petrussa et al. 2014) (Table 2). It is therefore assumed that methylated loci in human oocytes recruit DNMT3A directly via their PWWP domain that recognizes H3K36me3 (Dhayalan et al. 2010).

\section{Genomic imprinting}

Genomic imprinting refers to the epigenetic mechanism that results in the parent-of-origin monoallelic expression of autosomal genes (Monk 2015). It is a particularly unique epigenetic mechanism, since an individual somatic cell has both active and repressed alleles of the same gene. Imprinted differentially methylated regions (DMRs) are established in the male and female gametes. However, the specific aspect that makes imprinted DMRs unique is not their germline status, but their ability to maintain parent-of-origin allelic methylation during pre-implantation reprogramming (Smallwood et al. 2011, Smith et al. 2014). To date, there are 38 known germline-derived imprinted DMRs in humans, the majority originating in the oocyte, that retain life-long allelic methylation in adult tissues (Monk et al. 2016). It has been shown that imprinted DMRs are selectively protected from the demethylation that occurs in the zygote immediately after fertilization. The paternal pronucleus is rapidly demethylated by the oxidative action of 10-11 translocation protein 3 (TET3) that converts 5-methylcytosine $(5 \mathrm{mC})$ to 5 -hydromethylcytosine $(5 \mathrm{hmC})$, in a process that is finished before the completion of the first mitotic division (Wossidlo et al. 2011). Conversely, the demethylation process in the maternal pronucleus is more gradual and replication dependent. The maternal genome, including maternally methylated imprinting DMRs, is protected from TET3-mediated $5 \mathrm{mC}$ oxidation by developmental pluripotency-associated 3 (DPPA3) (also known as Stella or Pgc7), which specifically interacts with H3K9me2 enriched in the maternal, but not paternal, pronucleus

Table 2 Summary of the differences between mouse and human SCMC and imprinting highlighted in this review.

\begin{tabular}{|c|c|c|}
\hline Difference & Observation in mouse & Observation in humans \\
\hline DNMT3L expression in oocytes & $\begin{array}{l}\text { Expressed in oocytes and essential for the } \\
\text { establishment of maternal methylation }\end{array}$ & DNMT3L is not expressed in human oocytes \\
\hline $\begin{array}{l}\text { Phenotype associated with } \\
\text { mutations in SCMC members }\end{array}$ & $\begin{array}{l}\text { Primarily cause early embryonic arrest at } \\
\text { early cleavage stages, no evidence of } \\
\text { molar pregnancies }\end{array}$ & $\begin{array}{l}\text { Early cleavage-stage arrest or hydatidiform moles, depending } \\
\text { on which member of the complex is affected }\end{array}$ \\
\hline NLRP7 & No N/rp7 in the murine genome & $\begin{array}{l}\text { NLRP7 is a paralogue of NLRP2 arising from evolutionary } \\
\text { duplication }\end{array}$ \\
\hline Phenotype associated with NLRP2 & $\begin{array}{l}\text { Mid-gestation embryo lethality in } \\
\text { pregnancies of NIrp2 } 2^{-1-} \text { females }\end{array}$ & $\begin{array}{l}\text { Rare cases of MLID and Beckwith-Wiedemann Syndrome in } \\
\text { children of women carrying mutations }\end{array}$ \\
\hline Phenotype associated with NLRP5 & $\begin{array}{l}\text { Embryos of female N/rp5 } 5^{-/-} \text {mice arrest at } \\
\text { the pre-implantation cleavage stages }\end{array}$ & $\begin{array}{l}\text { Women with mutations have varied reproductive histories, } \\
\text { suffering from recurrent pregnancy loss, hydatidiform } \\
\text { moles as well as live-born children with MLID }\end{array}$ \\
\hline Placenta-specific imprinting & $\begin{array}{l}\text { No placenta-specific maternally methyl- } \\
\text { ated imprinted DMRs }\end{array}$ & $\begin{array}{l}\text { Oocyte-derived methylation associated with maternally } \\
\text { methylated placenta imprints }\end{array}$ \\
\hline
\end{tabular}


(Nakamura et al. 2012). Both maternally and paternally methylated imprinted DMRs are further protected from pre-implantation reprogramming by the sequencespecific factor zinc finger protein 57 (ZFP57) (Li et al. 2008b). This kruppel-associated box-containing zinc finger protein recruits the Tripartite motif-containing 28 (TRIM28) repressor complex (Quenneville et al. 2011) and is therefore responsible for targeting DNMT1 to specific loci at a time when most of this protein is located in the cytoplasm.

\section{The subcortical maternal complex}

The subcortical maternal complex (SCMC) is a multiprotein complex expressed in oocytes and preimplantation embryos, essential for zygote progression beyond the first embryonic cell divisions (Bebbere et al. 2016). In humans, it is currently composed of at least four known oocyte-derived proteins: oocyte-expressed protein (OOEP; also known as Factor Located in Oocytes Permitting Embryonic Development, FLOPED), Transducin-Like Enhancer of Split 6 (TLE6), NLR family, Pyrin domain-containing 5 (NLRP5; also known as Maternal Antigen That Embryos Require, MATER) and $\mathrm{KH}$ Domain Containing 3-Like (KHDC3L; also known as ES Cell-Associated Transcript I, ECAT1, C6ORF221 or FILIA) (Zhu et al. 2015). These proteins localise to the subcortical region in mouse and human oocytes and pre-implantation embryos are excluded from regions of cell-to-cell contact from the zygote onwards and are devoid from the inner cell mass of the blastocysts ( $\mathrm{Li}$ et al. 2008a).

All transcripts of the SCMC are encoded by maternaleffect genes, a class of genes coding for transcripts expressed exclusively in oocytes and early embryos and essential for the early embryonic development (Bebbere et al. 2016). They are highly abundant in the oocyte and early embryo and usually degraded by the time of EGA without transcriptional compensation from the embryonic genome (Tong et al. 2004, Ohsugi et al. 2008, Li et al. 2010). Consistent with their spatial and temporal expression profiles, targeted mice lacking individual proteins of the SCMC arrest between zygotic and cleavage stages (Tong et al. 2000, Li et al. 2008a, Tashiro et al. 2010). Therefore, the resulting female sterility is not due to aberrant folliculogenesis, ovulation, fertilization or uterine receptivity but the lack of maternal SCMC RNA/protein reserves required by the zygote to survive until EGA. However, despite the recent focus, the precise biological roles of the components of the SCMC are largely unknown.

One of the first characterised maternal-effect genes in mice was Nlrp5 (Tong et al. 2000), which was later found to physically interact with KHDC3L (Ohsugi et al. 2008). Subsequent screening for additional maternaleffect genes identified Dppa3 (Payer et al. 2003), peptidyl arginine deiminase 6 (PADI6) (Esposito et al. 2007) and Ooep (Li et al. 2008a). Dppa3 is not a member of the SCMC complex since the protein is found in both the cytoplasm and nucleus of oocytes with pronounced localisation in the pronuclei following fertilization (Sato et al. 2002). Recent detailed protein-protein interaction studies have confirmed that, in addition to oocytes and embryos co-localisation, that OOEP physically binds to NLRP5 and to TLE6, whilst KHDC3L interacts independently with NLRP5 to collectively form the SCMC (Li et al. 2008a,b). However the combined molecular weight of the known SCMC proteins (NLRP5 125 kDa; KHDC3L $~ 38 \mathrm{kDa}$; OOEP $\sim 18 \mathrm{kDa}$; TLE6 $\sim 65 \mathrm{kDa}$ ) is less than that observed by fast protein liquid chromatography gel filtration (between 669 and $2000 \mathrm{kDa}$ ) suggesting that there are additional SCMC proteins and interacting partners to be identified, the subcortical localisation of PADI6 implicating it as a potential member ( $\mathrm{Li}$ et al. $2008 a, b)$. With the exception of KHDC3L, genetic ablation of other SCMC components destabilises the complex, resulting in dispersed protein localisation that suggests these proteins are tightly regulated and function as an entire complex. This is further endorsed by the demonstration that both KHDC3L and the OOEP, NLRP5 and TLE6-complex play an important role in correct spindle assembly, the OOEP, NLRP5 and TLE6-complex controlling spindle position to ensure symmetrical cell division by regulating the dynamics of F-actin in the mouse zygotes (Zheng \& Dean 2009, Yu et al. 2014) (Fig. 2).

\section{Maternal-effect mutations in members of the SCMC}

Consistent with the early cleavage arrest observed in mouse mutants, recessive mutations in TLE6 and PADI6 have been identified in females undergoing fertility treatment. Women carrying mutated alleles were identified during a cohort screening of couples

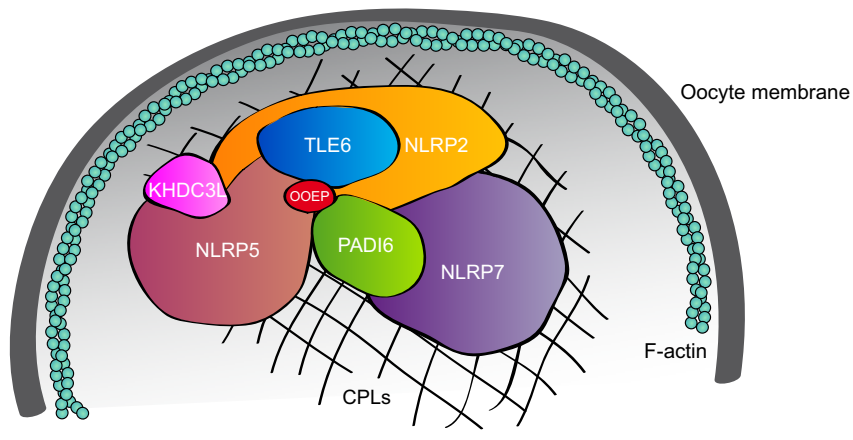

Figure 2 The hypothetical structure of the SCMC complex localised adjacent to the oocyte membrane. The SCMC interacts with both F-actin and the oocyte cytoplasmic lattices. The protein-protein interactions shown are deduced from co-immunoprecipitation experiments, although not all interactions for NLRP2 and NLRP7 have been assessed. 
who had multiple failed IVF and ICSI cycles specifically associated with recurrent embryonic developmental arrest (pre-implantation embryonic lethality (MIM: 616814)). Mutations in TLE6 were shown to cause the earliest known human embryonic lethality by affecting progression of oocyte meiosis II to zygote formation (Alazami et al. 2015), individuals with the mutations having a markedly impaired binding capacity for SCMC component proteins. Mutations in the PADI6 gene were shown to cause early embryonic arrest by the 4-cell stage, potentially impairing EGA (Xu et al. 2016). Women with loss-of-function mutations in NLRP5 have varied reproductive histories, suffering from recurrent pregnancy loss, possible molar pregnancies as well as live-born children with abnormal epigenetic profiles at imprinted loci (Docherty et al. 2015). Interestingly, women with KHDC3L mutations also experience multiple reproductive failures predominantly a rare recurrent form of biparental hydatidiform mole (BiHM) (HYDM1; OMIM\# 231090) (Parry et al. 2011).

\section{Biparental hydatidiform moles}

Complete hydatidiform moles ( $\mathrm{CHM})$ are an abnormal human pregnancy classically characterised by the absence of embryonic development, hydropic degeneration of the choronic villi of the placenta and hyperplasia of the villous trophoblast. CHM are commonly sporadic and diploid androgenetic with the majority resulting from a monospermic fertilization event followed by genome duplication without cytokinesis and a minority, 10-20\%, by a dispermic event (Hoffner \& Surti 2012). The fate of the maternal chromosomes in $\mathrm{CHM}$ is unclear. An error during meiosis could give rise to an anucleate egg. However, it has been argued that evidence for a reservoir of anuclear oocytes is lacking and that $\mathrm{CHM}$ might actually arise as a result of postzygotic diploidisation of a triploid conceptus.

Occasionally, HM can be recurrent and familial in nature consistent with an autosomal condition resulting in a predisposition to CHM (Fisher et al. 2004). Cases of familial recurrent HM (FRHM) are extremely rare, but the condition can be identified by demonstrating that pregnancies which are morphologically $\mathrm{CHM}$ are diploid and biparental or, rarely, digynic triploids (Fallahian et al. 2013, Nguyen \& Slim 2014) rather than androgenetic diploids. While FRHM may result from mutations in KHDC3L (Parry et al. 2011), this accounts for only $5-10 \%$ of cases, mutations in another maternal-effect gene, NLRP7 having been shown to account for approximately $75 \%$ of cases (Murdoch et al. 2006). Ten years following the initial reports of NLRP7 being responsible for recurrent $\mathrm{BiHM}, \sim 60$ pathogenic variants have been reported in females homozygous or compound heterozygous for these defective alleles. These include missense mutations, nonsense mutations, splice site mutations and Alu-mediated deletions (Wang et al. 2009, Dixon et al. 2012, Reddy et al. 2016).

Like mutations in NLRP7, mutations in KHDC $3 L$ may occur in single affected individuals or multiple members of a large family and affected individuals may be homozygous or compound heterozygotes. To date, most mutations in $K H D C 3 L$ have been found to be small deletions, with two variants affecting the initiation codon and a single variant giving rise to a splice site mutation (Parry et al. 2011, Reddy et al. 2013, Rezaei et al. 2016).

\section{Other pregnancy outcomes associated with NLRP7 maternal-effect mutations}

While approximately $75 \%$ of pregnancies in women with FRHM are CHM (Fisher et al. 2004), variable pregnancy outcomes have been reported in a minority of cases of women with recessive NLRP7 mutations, including stillbirth, early spontaneous pregnancy loss, partial HM and androgenetic CHM. Similarly, spontaneous abortions have been reported in women with KHDC3L mutations. Intriguingly, occasional live births have been documented to date in women with homozygous NLRP7 mutations (Akoury et al. 2015b), while no live births have been reported among women with two defective KHDC3L alleles (Parry et al. 2011, Reddy et al. 2013, Rezaei et al. 2016). For women with NLRP7 mutations who wish to achieve a normal pregnancy, in vitro fertilization with ovum donation has been shown to provide a viable option (Fisher et al. 2011, Akoury et al. 2015b)

It has recently been suggested that heterozygous mutations in NLRP7 may be associated with other forms of reproductive failure other than BiHM, such as recurrent miscarriage and sporadic $\mathrm{CHM}$ (Messaed et al. 2011). However, mutation screening in women with a diagnosis of primary unexplained infertility or with unexplained recurrent miscarriage failed to identify pathological variants in NLRP7 or KHDC3L suggesting that mutation in these genes are not a common cause of recurrent pregnancy loss (Aghajanova et al. 2015).

\section{Widespread imprinting defects in NLRP7- associated moles}

The characteristic morphological features of sporadic $\mathrm{CHM}$ result from their androgenetic origin with the consequent overexpression of paternally transcribed genes with potential loss of maternally transcribed genes. Since $\mathrm{BiCHM}$ are morphologically similar, and in many cases indistinguishable, from androgenetic $\mathrm{CHM}$, imprinting defects are likely to underlie their development. Consistent with this is an absence of expression of $\mathrm{p} 57$, the product of the maternally transcribed gene CDKN1C in both androgenetic and BiHM (Fisher et al. 2002). Initial epigenetic studies in 


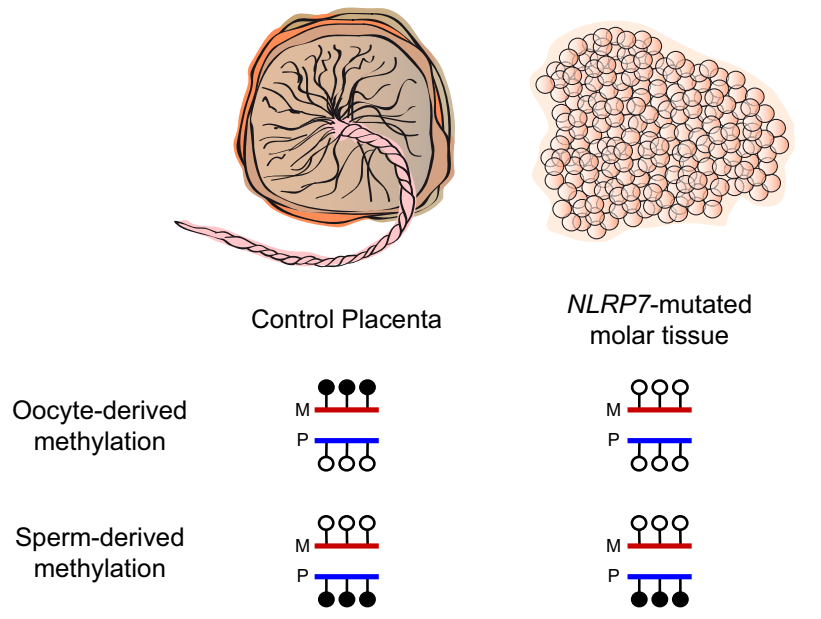

molar tissue from women carrying recessive NLRP7 mutations have revealed aberrant DNA methylation profiles at a limited number of imprinted genes (El-Maarri et al. 2003, Kou et al. 2008, Hayward et al. 2009). Similarly, investigation of a single BiHM from a woman, later found to be homozygous for mutations in $K H D C 3 L$, identified a number of imprinted genes to be aberrantly expressed (Judson et al. 2002). Lack of allelic methylation in NLRP7-associated BiHM was consistently noted for maternally methylated imprinted regions, including the differentially methylated regions (DMRs) associated with PEG3, SNRPN, KCNQ1OT1, MEST and GNAS. Consistent with a fertilisation event with a normal sperm, the paternally methylated H19 region was normally methylated in BiHM. Curiously, maternal methylation at the PEG 10 DMR seems to maintain allelic methylation with a profile similar to control placentas, suggesting that imprinting at this locus is established by a different mechanism (Hayward et al. 2009, SanchezDelgado et al. 2015).

Recently, BiHM tissues from females with recessive NLRP7 mutations have been screened for methylation defects using high-density methylation arrays. Using this approach, Sanchez-Delgado and colleagues reported that the majority of maternally methylated DMRs are hypomethylated, with some notable exceptions. For example the DMRs associated with IGF1R and RB1 maintained methylation in all BiHM samples, whereas the PLAGL1, PEG10 and NAP1L5 DMRs retained allelic methylation in a stochastic fashion (Sanchez-Delgado et al. 2015). Intriguingly, complete hypomethylation was also observed at 48 placenta-specific imprinted loci suggesting that the molar phenotype could largely be due to genome-wide disruption of genomic imprinting (Fig. 3).

\section{Are other NLRP proteins SCMC members?}

Remarkably, maternal loss-of-function of two highly homologous genes, NLRP2 and NLRP7, which like NLRP5 encode NLR family proteins, are highly

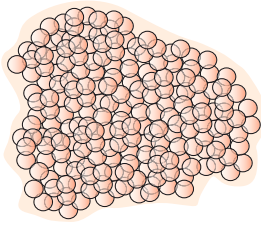

Androgenetic derived molar tissue

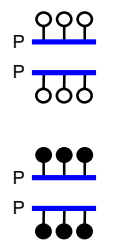

Figure 3 Profiles at imprinted differentially methylated regions in placenta and hydatidiform moles. In normal placental tissue oocyte-derived methylation is maintained on the maternal allele at imprinted DMRs, while reciprocally sperm-derived methylation is observed exclusively on the paternal allele. In both androgenetic and NLRP7-associated molar tissues there is complete loss of methylation at the majority of maternal DMRs. However paternal DMRs can differentiate androgenetic from NLRP7-associated moles. Methylation will appear hypermethylated in androgenetic moles due to the two copies of associated moles as a result of a biparental fertilization. the paternal genome and normal in NLRP7-

expressed in oocytes and pre-implantation embryos (Zhang et al. 2008) and associated with various forms of reproductive wastage. Maternal mutations in NLRP2 have been described in a mother with two offspring affected with Beckwith-Wiedemann syndrome and one multi-locus imprinting disturbance (MLID), although the full extent of the methylation defects was not reported (Meyer et al. 2009), while mid-gestation embryos from $\mathrm{Nlrp}^{-1-}$ female mice exhibit a range of methylation abnormalities at imprinted loci (Mahadevan et al. 2017). NLRP7 is highly homologous to NLRP2 and the two genes adjacent to each other on chromosome 19. NLRP7 does not have an orthologue in mice, but is thought to have originated from a direct evolutionary duplication of NLRP2 (Duèñez-Guzmán \& Haig 2014). As discussed earlier, maternal mutations in NLRP7, like those in KHDC $3 L$, have been shown to be associated with poor reproductive outcomes, specifically complete molar pregnancies (Murdoch et al. 2006, Wang et al. 2009, Parry et al. 2011). Consistent with SCMC protein expression patterns, NLRP7 co-localises with KHDC3L to the cortical region in oocyte and 2-cell embryos, but not to regions of cell-to-cell contact (Akoury et al. 2015a). Murine NLRP2 has also been shown to be located in the subcortical layer and to interact with multiple SCMC proteins (Mahadevan et al. 2017) suggesting that, in addition to NLRP5, both NLRP2 and NLRP7 may also be bona fide SCMC proteins (Fig. 2).

\section{Potential SCMC-NLRP epigenetic function}

It is surprising that SCMC-NLRP proteins have potentially different roles in imprint establishment or maintenance. The broad loss of maternally methylated imprints, whilst paternally methylated DMRs are unaffected, implicate NLRP7 in oocyte-specific methylation establishment (Sanchez-Delgado et al. 2015). However, both maternally and paternally methylated imprinted DMRs are affected in MLID patients resulting from NLRP5 mutations (Docherty et al. 2015) and in offspring from 
Nlrp2 ${ }^{-/-}$female mice, suggesting roles in post-zygotic maintenance (Mahadevan et al. 2017). In addition $N L R P 2$ and NLRP7 show a different temporal expression pattern in human pre-implantation embryos from NLRP5, an increase in expression between days 3 and 5 being observed for the former but not NLRP5 (Zhang et al. 2008). What makes the participation of these NLRPs in the imprinting process even more extraordinary is that the SCMC-NLRP proteins have an exclusive cytoplasmic localization while DNA methylation is a nuclear process. This may be explained by the additional functions of the SCMC that have been revealed in mutant mice, namely the degradation of maternal RNA and protein stores (Wang et al. 2012). In addition to the release of the maintenance methyltransferase, DNMT1, from its normal subcortical localization in the oocytes of NIrp2 $2^{-/-}$ females (Mahadevan et al. 2017), it could be speculated that stores of other maternal-effect proteins involved in the imprinting process, such as DPPA3, TRIM28 and ZFP57 (Nakamura et al. 2007, Li et al. 2008b, Messerschmidt et al. 2012), may also be mislocalized, depleted or perhaps inappropriately degraded during cleavage embryo development. Alternatively, NLRP7SCMC may ensure the correct cellular localization and nuclear translocation of epigenetic factors during oocyte development. Immunostaining for the two mammalian de novo methyltransferases DNMT3A and DNMT3B has revealed that, like DNMT1, they also have a cytoplasmic localization in human oocytes (Petrussa et al. 2014). This suggests that low abundant protein complexes containing the DNMTs may associate to specific DNA sequences possibly by direct interaction with known NLRP7-interacting chromatin regulators YY1 (Mahadevan et al. 2014) or ZBTB16 (Singer et al. 2015).

\section{Developmental discrepancies, speculations and conclusions}

The vigilant readers of this review will have noted several developmental inconsistencies between mouse models and the equivalent human phenotypes. While maternal-effect mutations in TLE6 and PADI6 have similar outcomes in humans as exhibited by murine models, differences exist for other maternal-effect genes. These include (i) the offspring of $\mathrm{Nlrp}^{-/-}$mice, which arrest at the cleavage stage, whereas NLRP5 maternal-effect mutations are associated with varying reproductive outcomes and MLID; (ii) female N/rp2 $2^{-/-}$ mice are sub-fertile, with most pregnancies ending in embryonic lethality. In the rare cases that pups are produced, they die shortly after birth. In humans, maternal-effect mutations of NLRP2 have been shown to result in MLID. It is possible that in human cases, the true incidence of the mutations is under presented, with the majority of the conspecti being lost before pregnancy was detected. In the rare instances that liveborn children are observed, the development progresses due to the stochastic nature of the MLID. Similarly, the true impact of N/pr2 on imprinted methylation in mice may also be underestimated as the work reported by Mahadevan and coworkers was performed on rare embryos that developed to embryonic day 9.5 and not on pre-implantation embryos where the most extreme developmental phenotypes would be anticipated (Mahadevan et al. 2017). It is likely that the mid-gestation embryos reflect those with minor/viable imprinting defects and that widespread methylation anomalies would be restricted to the earlier arrested embryos.

In women with homozygous or compound heterozygous mutations in NLRP7 most recognised pregnancies develop as BiHM with a regular diploid karyotype. In in vitro studies, NLRP7 mutations have also been observed to cause early embryonic developmental arrest. Two studies have reported the in vitro development of embryos following assisted reproductive cycles in women carrying recessive NLRP7 mutations (Deveault et al. 2009, Sills et al. 2017). Both studies reported high rates of mosaic, haploid-diploid and haploid-maternal aneuploid embryos, with the majority of embryos degenerating before the blastocysts stage suggesting that BiHM may result from preferential selection of cells with widespread imprinting errors without ploidy errors. Careful counselling is advised in the case of a woman with FRHM as conventional in vitro fertilization with PGD will be unable to distinguish a $\mathrm{BiCHM}$ from a normal pregnancy. For these women, the use of donor oocytes is encouraged since successful pregnancies have been achieved in women with underlying NLPR7 mutations (Fisher et al. 2011, Akoury et al. 2015a,b).

While mutations in members of the SCMC clearly implicate the complex in establishing or maintaining maternal epigenetic marks during oogenesis and early fetal development, the mechanisms by which this is achieved remains unclear and is likely to be different in different species. While both NLRP2 and NLRP7 are potential members of the SCMC, the size of the SCMC suggests there may be other, as yet unidentified, members. Identification of novel members of the SCMC is needed to provide greater insight into the role of the SCMC in the establishment and maintenance of the maternal imprint in early embryogenesis and reproductive loss.

\section{Declaration of interest}

The authors declare that there is no conflict of interest that could be perceived as prejudicing the impartiality of this review.

\section{Funding}

This work was supported by the Spanish Ministerio de Educación y Competitividad (MINECO) (BFU2014-53093 to $\mathrm{D}$ M) co-funded with the European Union Regional Development Fund (FEDER). 


\section{Acknowledgements}

The authors are grateful to members of the Monk laboratory for helpful discussions.

\section{References}

Aghajanova L, Mahadevan S, Altmäe S, Stavreus-Evers A, Regan L, Sebire N, Dixon P, Fisher RA \& Van den Veyver IB 2015 No evidence for mutations in NLRP7, NLRP2 or KHDC3L in women with unexplained recurrent pregnancy loss or infertility. Human Reproduction $\mathbf{3 0}$ 232-238. (doi:10.1093/humrep/deu296)

Akoury E, Zhang L, Ao A \& Slim R 2015a NLRP7 and KHDC3L, the two maternal-effect proteins responsible for recurrent hydatidiform moles, co-localize to the oocyte cytoskeleton. Human Reproduction $\mathbf{3 0}$ 159-169. (doi:10.1093/humrep/deu291)

Akoury E, Gupta N, Bagga R, Brown S, Déry C, Kabra M, Srinivasan R \& Slim R 2015b Live births in women with recurrent hydatidiform mole and two NLRP7 mutations. Reproductive BioMedicine Online 31 120-124. (doi:10.1016/j.rbmo.2015.03.011)

Alazami AM, Awad SM, Coskun S, Al-Hassan S, Hijazi H, Abdulwahab FM, Poizat C \& Alkuraya FS 2015 TLE6 mutation causes the earliest known human embryonic lethality. Genome Biology 16 240. (doi:10.1186/ s13059-015-0792-0)

Amleh A \& Dean J 2002 Mouse genetics provides insight into folliculogenesis, fertilization and early embryonic development. Human Reproduction Update 8 395-403. (doi:10.1093/humupd/8.5.395)

Baubec T, Colombo DF, Wirbelauer C, Schmidt J, Burger L, Krebs AR, Akalin A \& Schübeler D 2015 Genomic profiling of DNA methyltransferases reveals a role for DNMT3B in genic methylation. Nature 520 243-247. (doi:10.1038/nature14176)

Bebbere D, Masala L, Albertini DF \& Ledda S 2016 The subcortical maternal complex: multiple functions for one biological structure? Journal of Assisted Reproduction and Genetics 33 1431-1438. (doi:10.1007) s10815-016-0788-z)

Bourc'his D, Xu GL, Lin CS, Bollman B \& Bestor TH 2001 Dnmt3L and the establishment of maternal genomic imprints. Science 294 2536-2539.

Chotalia M, Smallwood SA, Ruf N, Dawson C, Lucifero D, Frontera M, James K, Dean W \& Kelsey G 2009 Transcription is required for establishment of germline methylation marks at imprinted genes. Genes and Development 23 105-117. (doi:10.1101/gad.495809)

Ciccone DN, Su H, Hevi S, Gay F, Lei H, Bajko J, Xu G, Li E \& Chen T 2009 KDM1B is a histone H3K4 demethylase required to establish maternal genomic imprints. Nature 461 415-418. (doi:10.1038/nature08315)

Clift D \& Schuh M 2013 Restarting life: fertilization and the transition from meiosis to mitosis. Nature Reviews Molecular Cell Biology 14 549-562. (doi:10.1038/nrm3643)

Deveault C, Qian JH, Chebaro W, Ao A, Gilbert L, Mehio A, Khan R, Tan SL, Wischmeijer A, Coullin P et al. 2009 NLRP7 mutations in women with diploid androgenetic and triploid moles: a proposed mechanism for mole formation. Human Molecular Genetics 18 888-897. (doi:10.1093/ hmg/ddn418)

Dhayalan A, Rajavelu A, Rathert P, Tamas R, Jurkowska RZ, Ragozin S \& Jeltsch A 2010 The Dnmt3a PWWP domain reads histone 3 lysine 36 trimethylation and guides DNA methylation. Journal of Biological Chemistry 285 26114-26120. (doi:10.1074/jbc.M109.089433)

Dixon PH, Trongwongsa P, Abu-Hayyah S, Ng SH, Akbar SA, Khawaja NP, Seckl MJ, Savage PM \& Fisher RA 2012 Mutations in NLRP7 are associated with diploid biparental hydatidiform moles, but not androgenetic complete moles. Journal of Medical Genetics 49 206-211. (doi:10.1136/jmedgenet-2011-100602)

Docherty LE, Rezwan FI, Poole RL, Turner CL, Kivuva E, Maher ER, Smithson SF, Hamilton-Shield JP, Patalan M, Gizewska M et al. 2015 Mutations in NLRP5 are associated with reproductive wastage and multilocus imprinting disorders in humans. Nature Communications 6 8086. (doi:10.1038/ncomms9086)

Duéñez-Guzmán EA \& Haig D 2014 The evolution of reproduction-related NLRP genes. Journal of Molecular Evolution 78 194-201. (doi:10.1007/ s00239-014-9614-3)
El-Maarri O, Seoud M, Coullin P, Herbiniaux U, Oldenburg J, Rouleau G \& Slim R 2003 Maternal alleles acquiring paternal methylation patterns in biparental complete hydatidiform moles. Human Molecular Genetics 12 1405-1413. (doi:10.1093/hmg/ddg152)

Esposito G, Vitale AM, Leijten FP, Strik AM, Koonen-Reemst AM, Yurttas P, Robben TJ, Coonrod S \& Gossen JA 2007 Peptidylarginine deiminase (PAD) 6 is essential for oocyte cytoskeletal sheet formation and female fertility. Molecular and Cellular Endocrinology 273 25-31. (doi:10.1016/j.mce.2007.05.005)

Fallahian M, Sebire NJ, Savage PM, SeckI MJ \& Fisher RA 2013 Mutations in NLRP7 and KHDC3L confer a complete hydatidiform mole phenotype on digynic triploid conceptions. Human Mutation 34 301-308. (doi:10.1002/humu.22228)

Fisher RA, Hodges MD, Rees HC, Sebire NJ, Seckl MJ, Newlands ES, Genest DR \& Castrillon DH 2002 The maternally transcribed gene p57KIP2 (CDNK1C) is abnormally expressed in both androgenetic and biparental complete hydatidiform moles. Human Molecular Genetics 11 3267-3272. (doi:10.1093/hmg/11.26.3267)

Fisher RA, Hodges MD \& Newlands ES 2004 Familial recurrent hydatidiform mole: a review. Journal of Reproductive Medicine 49 595-601.

Fisher RA, Lavery SA, Carby A, Abu-Hayyeh S, Swingler R, Sebire NJ \& Seckl MJ 2011 What a difference an egg makes. Lancet 3781974. (doi:10.1016/S0140-6736(11)61751-0)

Gahurova L, Tomizawa SI, Smallwood SA, Stewart-Morgan KR, Saadeh H, Kim J, Andrews SR, Chen T \& Kelsey G 2017 Transcription and chromatin determinants of de novo DNA methylation timing in oocytes. Epigenetics and Chromatin 10 25. (doi:10.1186/s13072-017-0133-5)

Hayward BE, De Vos M, Talati N, Abdollahi MR, Taylor GR, Meyer E, Williams D, Maher ER, Setna F, Nazir K et al. 2009 Genetic and epigenetic analysis of recurrent hydatidiform mole. Human Mutation $\mathbf{3 0}$ E629-E639. (doi:10.1002/humu.20993)

Hoffner L \& Surti U 2012 The genetics of gestational trophoblastic disease: a rare complication of pregnancy. Cancer Genetics 205 63-77. (doi:10.1016/j.cancergen.2012.01.004)

Judson H, Hayward BE, Sheridan E \& Bonthron DT 2002 A global disorder of imprinting in the human female germ line. Nature 416 539-542. (doi:10.1038/416539a)

Kaneda M, Okano M, Hata K, Sado T, Tsujimoto N, Li E \& Sasaki H 2004 Essential role for de novo DNA methyltransferase Dnmt3a in paternal and maternal imprinting. Nature 429 900-903. (doi:10.1038/nature02633)

Kobayashi H, Sakurai T, Imai M, Takahashi N, Fukuda A, Yayoi O, Sato S, Nakabayashi K, Hata K, Sotomaru Y et al. 2012 Contribution of intragenic DNA methylation in mouse gametic DNA methylomes to establish oocyte-specific heritable marks. PLoS Genetics 8 e1002440. (doi:10.1371/journal.pgen.1002440)

Kou YC, Shao L, Peng HH, Rosetta R, del Gaudio D, Wagner AF, Al-Hussaini TK \& Van den Veyver IB 2008 A recurrent intragenic genomic duplication, other novel mutations in NLRP7 and imprinting defects in recurrent biparental hydatidiform moles. Molecular Human Reproduction 14 33-40. (doi:10.1093/molehr/gam079)

Li L, Baibakov B \& Dean J 2008a A subcortical maternal complex essential for preimplantation mouse embryogenesis. Developmental Cell $\mathbf{1 5}$ 416-425. (doi:10.1016/j.devcel.2008.07.010)

Li X, Ito M, Zhou F, Youngson N, Zuo X, Leder P \& Ferguson-Smith AC 2008b A maternal-zygotic effect gene, Zfp57, maintains both maternal and paternal imprints. Developmental Cell 15 547-557. (doi:10.1016/j. devcel.2008.08.014)

Li L, Zheng P \& Dean J 2010 Maternal control of early mouse development. Development 137 859-870. (doi:10.1242/dev.039487)

Mahadevan S, Wen S, Wan YW, Peng HH, Otta S, Liu Z, lacovino M, Mahen EM, Kyba M, Sadikovic B et al. 2014 NLRP7 affects trophoblast lineage differentiation, binds to overexpressed YY1 and alters CpG methylation. Human Molecular Genetics 23 706-716. (doi:10.1093/ hmg/ddt457)

Mahadevan S, Sathappan V, Utama B, Lorenzo I, Kaskar K \& Van den Veyver IB 2017 Maternally expressed NLRP2 links the subcortical maternal complex (SCMC) to fertility, embryogenesis and epigenetic reprogramming. Scientific Reports 7 44667. (doi:10.1038/srep44667)

Messerschmidt D, de Vries W, Ito M, Solter D, Ferguson-Smith A \& Knowles B 2012 Trim28 is required for epigenetic stability during mouse 
oocyte to embryo transition. Science 335 1499-1502. (doi:10.1126/ science.1216154)

Messaed C, Chebaro W, Di Roberto RB, Rittore C, Cheung A, Arseneau J, Schneider A, Chen MF, Bernishke K, Surti U et al. 2011 NLRP7 in the spectrum of reproductive wastage: rare non-synonymous variants confer genetic susceptibility to recurrent reproductive wastage. Journal of Medical Genetics 48 540-548. (doi:10.1136/jmg.2011.089144)

Meyer E, Lim D, Pasha S, Tee LJ, Rahman F, Yates JR, Woods CG, Reik W \& Maher ER 2009 Germline mutation in NLRP2 (NALP2) in a familial imprinting disorder (Beckwith-Wiedemann Syndrome). PLoS Genetics 5 e1000423. (doi:10.1371/journal.pgen.1000423)

Monk D 2015 Germline-derived DNA methylation and early embryo epigenetic reprogramming: the selected survival of imprints. International Journal of Biochemistry and Cell Biology 67 128-138. (doi:10.1016/j. biocel.2015.04.014)

Monk D, Morales J, den Dunnen JT, Russo S, Court F, Prawitt D, Eggermann T, Beygo J, Buiting K \& Tümer Z 2016 Recommendations for a nomenclature system for reporting methylation aberrations in imprinted domains. Epigenetics. Epub (doi:10.1080/15592294.2016.1264561)

Murdoch S, Djuric U, Mazhar B, Seoud M, Khan R, Kuick R, Bagga R, Kircheisen R, Ao A, Ratti B et al. 2006 Mutations in NALP7 cause recurrent hydatidiform moles and reproductive wastage in humans. Nature Genetics 38 300-302. (doi:10.1038/ng1740)

Nakamura T, Arai Y, Umehara H, Masuhara M, Kimura T, Tanigchi H, Sekimoto T, Ikawa M, Yoneda Y, Okabe M et al. 2007 PGC7/Stella protets against DNA demethylation in early embryogenesis. Nature Cell Biology 9 64-71. (doi:10.1038/ncb1519)

Nakamura T, Liu YJ, Nakashima H, Umehara H, Inoue K, Matoba S, Tachibana M, Ogura A, Shinkai Y \& Nakano T 2012 PGC7 binds histone $\mathrm{H} 3 \mathrm{~K}$ 9me2 to protect against conversion of $5 \mathrm{mC}$ to $5 \mathrm{hmC}$ in early embryos. Nature 486 415-419. (doi:10.1038/nature11093)

Nguyen N \& Slim R 2014 Genetics and epigenetics of recurrent hydatidiform moles: basic science and genetic counselling. Current Obstetrics and Gynecology Reports 3 55-64. (doi:10.1007/s13669-013-0076-1)

Ohsugi M, Zheng P, Baibakov B, Li L \& Dean J 2008 Maternally derived FILIA-MATER complex localizes asymmetrically in cleavage-stage mouse embryos. Development 135 259-269. (doi:10.1242/dev.011445)

Ooi SK, Qiu C, Bernstein E, Li K, Jia D, Yang Z, Erdjument-Bromage H, Tempst P, Lin SP, Allis CD, Cheng X \& Bestor TH 2007 DNMT3L connects unmethylated lysine 4 of histone $\mathrm{H} 3$ to de novo methylation of DNA. Nature 448 714-717. (doi:10.1038/nature05987)

Parry DA, Logan CV, Hayward BE, Shires M, Landolsi H, Diggle C, Carr I, Rittore C, Touitou I, Philibert L et al. 2011 Mutations causing familial biparental hydatidiform mole implicate c6orf221 as a possible regulator of genomic imprinting in the human oocyte. American Journal of Human Genetics 89 451-458. (doi:10.1016/j.ajhg.2011.08.002)

Payer B, Saitou M, Barton SC, Thresher R, Dixon JP, Zahn D, Colledge WH, Carlton MB, Nakano T et al. 2003 Stella is a maternal effect gene required for normal early development in mice. Current Biology 13 2110-2117. (doi:10.1016/j.cub.2003.11.026)

Petrussa L, Van de Velde H \& De Rycke M 2014 Dynamic regulation of DNA methyltransferases in human oocytes and preimplantation embryos after assisted reproductive technologies. Molecular Human Reproduction 20 861-874. (doi:10.1093/molehr/gau049)

Quenneville S, Verde G, Corsinotti A, Kapopoulou A, Jakobsson J, Offner S, Baglivo I, Pedone PV, Grimaldi G, Riccio A et al. 2011 In embryonic stem cells, ZFP57/KAP1 recognize a methylated hexanucleotide to affect chromatin and DNA methylation of imprinting control regions. Molecular Cell 4 361-372. (doi:10.1016/j.molcel.2011.08.032)

Reddy R, Akoury E, Phuong Nguyen NM, Abdul-Rahman OA, Dery C, Gupta N, Daley WP, Ao A, Landolsi H, Ann Fisher R et al. 2013 Report of four new patients with protein-truncating mutations in C6orf221/ KHDC3L and colocalization with NLRP7.European Journal of Human Genetics 21 957-964. (doi:10.1038/ejhg.2012.274)

Reddy R, Nguyen NM, Sarrabay G, Rezaei M, Rivas MC, Kavasoglu A, Berkil H, Elshafey A, Abdalla E, Nunez KP et al. 2016 The genomic architecture of NLRP7 is Alu rich and predisposes to disease-associated large deletions. European Journal of Human Genetics 241516. (doi:10.1038/ejhg.2016.96)

Rezaei M, Nguyen NM, Foroughinia L, Dash P, Ahmadpour F, Verma IC, Slim R \& Fardaei M 2016 Two novel mutations in the KHDC3L gene in Asian patients with recurrent hydatidiform mole. Human Genome Variation 3 16027. (doi:10.1038/hgv.2016.27)

Sanchez-Delgado M, Martin-Trujillo A, Tayama C, Vidal E, Esteller M, Iglesias-Platas I, Deo N, Barney O, Maclean K, Hata K et al. 2015 Absence of maternal methylation in biparental hydatidiform moles from women with NLRP7 maternal-effect mutations reveals widespread placenta-specific imprinting. PLoS Genetics 11 e1005644. (doi:10.1371/ journal.pgen.1005644)

Sanchez-Delgado M, Court F, Vidal E, Medrano J, Monteagudo-Sánchez A, Martin-Trujillo A, Tayama C, Iglesias-Platas I, Kondova I, Bontrop R et al. 2016 Human oocyte-derived methylation differences persist in the placenta revealing widespread transient imprinting. PLoS Genetics 12 e1006427. (doi:10.1371/journal.pgen.1006427)

Sato M, Kimura T, Kurokawa K, Fujita Y, Abe K, Masuhara M, Yasunaga T, Ryo A, Yamamoto M \& Nakano T 2002 Identification of PGC7, a new gene expressed specifically in preimplantation embryos and germ cells. Mechanisms of Development 113 91-94. (doi:10.1016/S09254773(02)00002-3)

Sills ES, Obregon-Tito AJ, Gao H, McWilliams TK, Gordon AT, Adams CA \& Slim R 2017 Pathogenic variant in NLRP7 (19q13.42) associated with recurrent gestational trophoblastic disease: Data from early embryo development observed during in vitro fertilization. Clinical and Experimental Reproductive Medicine 44 40-46. (doi:10.5653/ cerm.2017.44.1.40)

Singer H, Biswas A, Nuesgen N, Oldenburg J \& El-Maarri O 2015 NLRP7, involved in hydatidiform molar pregnancy (HYDM1), interacts with the transcriptional repressor ZBTB16. PLOS ONE 10 e0130416. (doi:10.1371/journal.pone.0130416)

Smallwood SA, Tomizawa S, Krueger F, Ruf N, Carli N, Segonds-Pichon A, Sato S, Hata K, Andrews SR \& Kelsey G 2011 Dynamic CpG island methylation landscape in oocytes and preimplantation embryos. Nature Genetics 43 811-814. (doi:10.1038/ng.864)

Smith ZD, Chan MM, Humm KC, Karnik R, Mekhoubad S, Regev A, Eggan K \& Meissner A 2014 DNA methylation dynamics of the human preimplantation embryo. Nature 511 611-615. (doi:10.1038/ nature13581)

Tashiro F, Kanai-Azuma M, Miyazaki S, Kato M, Tanaka T, Toyoda S, Yamato E, Kawakami H, Miyazaki T \& Miyazaki J 2010 Maternal-effect gene Ces5/Ooep/Moep19/Floped is essential for oocyte cytoplasmic lattice formation and embryonic development at the maternal-zygotic stage transition. Genes to Cells 15 813-828. (doi:10.1111/j.13652443.2010.01420.x)

Tong ZB, Gold L, Pfeifer KE, Dorward H, Lee E, Bondy CA, Dean J \& Nelson LM 2000 Mater, a maternal effect gene required for early embryonic development in mice. Nature Genetics 26 267-268. (doi:10.1038/81547)

Tong ZB, Gold L, De Pol A, Vanevski K, Dorward H, Sena P, Palumbo C, Bondy CA \& Nelson LM 2004 Developmental expression and subcellular localization of mouse MATER, an oocyte-specific protein essential for early development. Endocrinology 145 1427-1434.

Veselovska L, Smallwood SA, Saadeh H, Stewart KR, Krueger F, Maupetit-Méhouas S, Arnaud P, Tomizawa S, Andrews S \& Kelsey G 2015 Deep sequencing and de novo assembly of the mouse oocyte transcriptome define the contribution of transcription to the DNA methylation landscape. Genome Biology 16 209. (doi:10.1186/ s13059-015-0769-z)

Wang CM, Dixon PH, Decordova S, Hodges MD, Sebire NJ, Ozalp S, Fallahian M, Sensi A, Ashrafi F, Repiska V et al. 2009 Identification of 13 novel NLRP7 mutations in 20 families with recurrent hydatidiform mole; missense mutations cluster in the leucine rich region. Journal of Medical Genetics 46 569-575. (doi:10.1136/jmg.2008.064196)

Wang J, Xu M, Zhu K, Li L \& Liu X 2012 The N-terminus of FILIA forms an atypical $\mathrm{KH}$ domain with a unique extension involved in interaction with RNA. PLOS ONE 7 e30209. (doi:10.1371/journal.pone.0030209)

Wossidlo M, Nakamura T, Lepikhov K, Marques CJ, Zakhartchenko V, Boiani M, Arand J, Nakano T, Reik W \& Walter J 2011 5-Hydroxymethylcytosine in the mammalian zygote is linked with epigenetic reprogramming. Nature Communications 2241. (doi:10.1038/ncomms1240)

Xu Y, Shi Y, Fu J, Yu M, Feng R, Sang Q, Liang B, Chen B, Qu R, Li B et al. 2016 Mutations in PADI6 cause female infertility characterized by early 
embryonic arrest. American Journal of Human Genetics 99 744-752. (doi:10.1016/j.ajhg.2016.06.024)

Yu XJ, Yi Z, Gao Z, Qin D, Zhai Y, Chen X, Ou-Yang Y, Wang ZB, Zheng P, Zhu MS et al. 2014 The subcortical maternal complex controls symmetric division of mouse zygotes by regulating F-actin dynamics. Nature Communications 5 4887. (doi:10.1038/ncomms5887)

Zhang P, Dixon M, Zucchelli M, Hambiliki F, Levkov L, Hovatta O \& Kere J 2008 Expression analysis of the NLRP gene family suggests a role in human preimplantation development. PLOS ONE 3 e2755. (doi:10.1371/ journal.pone.0002755)

Zheng P \& Dean J 2009 Role of Filia, a maternal effect gene, in maintaining euploidy during cleavage-stage mouse embryogenesis. PNAS $\mathbf{1 0 6}$ 7473-7478. (doi:10.1073/pnas.0900519106)
Zhu K, Yan L, Zhang X, Lu X, Wang T, Yan J, Liu X, Qiao J \& Li L 2015 Identification of a human subcortical maternal complex. Molecular Human Reproduction 21 320-329. (doi:10.1093/molehr/gau116)

Received 28 July 2017

First decision 4 September 2017

Revised manuscript received 6 September 2017

Accepted 15 September 2017 